\title{
ADMINISTRAÇÃO PÚBLICA GERENCIAL E AS POSSIBILIDADES PARA A SOLUÇÃO EXTRAJUDICIAL DE CONFLITOS EM AGÊNCIAS REGULADORAS NO BRASIL
}

\section{Lara Caxico Martins Miranda* Marlene Kempfer**}

Resumo: A Emenda Constitucional n. 19 de 1998 criou possibilidades jurídicas para implementar a reforma do Estado, abrindo caminhos para que a eficiência, pilar da administração pública gerencial, fosse considerada no desempenho da função administrativa. Os parâmetros da gestão privada passam a servir de referência aos gestores públicos, como as soluções extrajudiciais de resolução de conflitos. Essas podem ser implementados no âmbito das agências reguladoras, porém faz-se necessário observar limites, em virtude do regime jurídico público aplicável. Apropriando-se do método dedutivo, em uma pesquisa bibliográfica, discute-se a atuação das agências reguladoras no que se refere à resolução extrajudicial de conflitos.

Palavras-chaves: Administração Gerencial. Agências Reguladoras. Arbitragem. Meios extrajudiciais de resolução de conflitos. Reforma do Estado.

\section{MANEGERIAL PUBLIC ADMINISTRATION AND THE POSSIBILITIES FOR THE EXTRAJUDICIAL SOLUTION OF CONFLICTS IN REGULATORY AGENCIES IN BRAZIL}

Abstract: The Constitutional Amendment n. 19 of 1998 created legal possibilities to implement State reform, opening up ways for efficiency, a pillar of the managerial public administration, to be considered in the performance of the administrative function. Private management pass on a reference service to public managers, such as out-of-court dispute resolution. These can be implemented within the regulatory agencies, but it is necessary to observe limits, due to the applicable public legal regime. Appropriating the deductive method,in a bibliographical research, the action of the regulatory agencies in the extrajudicial resolution of conflicts is discussed.

Key-words: Management Administration. Regulatory agencies. Arbitration. Extrajudicial means of resolving conflicts. Reform of the State.

\section{INTRODUÇÃO}

A sociedade brasileira alimenta, a cada dia, a expectativa de que os governos irão cumprir com seus deveres de modo a tornar reais as conquistas constitucionais que compõem um Estado de Direito, democrático e social. Neste sentido, faz-se importante o acesso e a

\footnotetext{
* Mestranda do Programa de Mestrado em Direito Negocial da Universidade Estadual de Londrina - UEL, (Brasil). E-mail: laracaxico@hotmail.com (https://orcid.org/0000-0002-0382-1715).

** Doutora em Direito do Estado pela Universidade Católica de São Paulo-PUC/SP, (Brasil). Professora do Mestrado em Direito Negocial e da Graduação da Universidade Estadual de Londrina/PR. E-mail: mkempferb@gmail.com.
} 
permanência nos serviços públicos, a viabilidade dos direitos sociais, bem como a intervenção do Estado sobre o domínio econômico em favor da convivência entre interesses privados e públicos.

As críticas à atuação dos governos, nos aspectos referidos, foi um dos estímulos que levou à aprovação da Emenda Constitucional n. 19 de 1998, denominada reforma administrativa. Essa incluiu o valor da eficiência no caput do artigo 37, que passa a compor expressamente regime jurídico da gestão dos interesses públicos. O sentido da eficiência, defende-se, quer imprimir à administração pública burocrata os mecanismos, institutos, técnicas e soluções que foram testadas na administração das empresas privadas. A eficiência passa a ser fundamento para os gestores públicos, com respaldo legal e regimental, cobrarem resultados, qualidade, descentralização, privatizações, agilidade e controle social. Estes são os pilares do regime jurídico público gerencial.

A pesquisa, que percorre estudos doutrinários e a análise de legislações, dedica-se às agências reguladoras, que se incluem na proposta da administração pública gerencial e consensual. Especificamente serão estudadas as suas atuações relativas às soluções extrajudiciais de conflitos e a consequente autorização legal concedida para que possam recorrer às técnicas da mediação e da arbitragem já praticadas no âmbito privado.

A questão que deve ser enfrentada, fundamentalmente, é se as técnicas referidas podem ser importadas para o âmbito público nos termos da Lei n. 9.307 de 1996 (e suas alterações) que dispõem sobre a arbitragem. Ademais, se mesmo não havendo previsão legal expressa sobre a utilização da mediação pelas agências reguladoras, é possível sua apropriação. Ainda, cumpre observar quais as adaptações que devem ser consideradas, uma vez que o gestor público está cercado da regra que impõem administrar conforme autoriza a lei, enquanto que o gestor privado tem liberdade para agir e respeitar os limites do que é proibido e obrigatório.

\section{OS PILARES DA REFORMA PARA CONSTRUIR A ADMINISTRAÇÃO PÚBLICA GERENCIAL E A EMENDA CONSTITUCIONAL N. 19 de 1988}

A reforma do aparelho do Estado se tornou tema central das discussões brasileiras a partir da década de 90 do século XX, em virtude dos reflexos no Brasil de uma realidade internacional de crise econômica, do processo de globalização e da abertura dos mercados. No plano interno, as crises inflacionária, fiscal e socioeconômica foram agravadas no que diz respeito ao Estado quanto prestador dos serviços públicos. 
Dentre tantos desafios, a presente pesquisa recorta a importância do debate sobre a atuação do Estado na prestação de serviços públicos, conforme artigo 175 da Constituição Federal de 1988 e na intervenção sobre o domínio econômico, conforme artigo 174 do mesmo instituto legal. Tanto na prestação de serviços públicos por meio da administração direta, indireta ou da iniciativa privada, quanto na intervenção normativa, fiscalizatória, de incentivo e de planejamento, fazia-se necessário "um serviço público moderno, profissional e eficiente, voltado para o atendimento das necessidades dos cidadãos" (BRESSER-PEREIRA, 1999, p. 17). Sob tal contexto, após dez anos da promulgação da Constituição Federal de 1988, essa foi alterada, de modo a positivar as diretrizes dos novos interesses do Estado: reformar para garantir eficiência.

A Emenda Constitucional n. 19 de 1998, marco legal da reforma do Estado, teve como objetivos incluir o princípio da eficiência entre os princípios da administração pública, criar a figura do contrato de gestão e ampliar e alterar competências administrativas dos órgãos do Estado. Além desses, propôs reestruturar o sistema de cargos públicos, fixando um teto salarial para cargos, empregos e funções públicas e prevendo a possibilidade de perda da estabilidade por avaliação de desempenho (MORAES, 1999, p. 16-37).

A emenda constitucional constituiu uma parte importante da reforma da gestão pública porque, além de criar as condições jurídicas e estabelecer alguns princípios básicos para a reforma, estimulou um debate nacional que acabou por modificar as concepções burocráticas brasileiras sobre a administração pública (BRESSER-PEREIRA, 2009, p. 149).

Além de outras importantes inovações, certamente, a eficiência administrativa foi um dos principais propósitos da reforma do aparelho do Estado. O poder-dever de administrar não poderia continuar sendo exercido apenas em vistas de se alcançar os resultados jurídicos antevistos pela lei. Havia a necessidade de que esses fossem praticados com excelência e com o objetivo de atender da melhor forma possível o cidadão.

O norte da eficiência administrativa foi encontrado na iniciativa privada e nos seus processos eficazes para o alcance de resultados. Apesar disso, “o contexto em que se insere a administração pública não se confunde com a administração privada donde tirou seu conceito, pois as demandas e objetivos são diversos" (BACELLAR, 2009, p. 20). Por essa razão, o princípio da eficiência, apesar de ter sido importado por meio da reforma gerencial, deve ser empregado em decisões subordinadas ao regime jurídico público. Esse garante o controle interno, externo, a responsabilização dos servidores e, em especial, o controle social, nos termos 
do artigo 37, $\S 3^{\circ}$ da Constituição da República Federativa do Brasil de 1988: participação do usuário dos serviços públicos na administração pública direta e indireta.

O administrador público precisa produzir não apenas o efeito previsto em lei, mas também o desejado e esperado pela sociedade. Deve garantir bons resultados por meio de uma atuação transparente, ética, imparcial, que atende indiscriminadamente à coletividade e que estimula a participação do povo na esfera pública. "Assim, o princípio da eficiência é o que impõe à administração pública direta e indireta e a seus agentes a persecução do bem comum" (MORAES, 1999, p. 30).

Apesar da inclusão do princípio da eficiência dentre os princípios da administração pública ter ocorrido apenas com a promulgação da Emenda Constitucional n. 19 de 1988, isso não significa que antes o Estado não devesse atuar dessa forma. A sua necessidade foi identificada já nas primeiras reformas administrativas vivenciadas pelo Estado brasileiro, que propunham o afastamento de princípios patrimoniais arraigados ao serviço público.

\subsection{Reformas administrativas brasileiras}

A primeira reforma administrativa reconhecida pela doutrina ocorreu durante o governo de Getúlio Vargas, na década de 30, com o ideário Estatal de participar diretamente das indústrias produtoras de matérias primas (indústrias de base), como siderurgia, metalurgia e petroquímica. Objetiva-se, com tal caminho, promover o desenvolvimento nacional e a modernização do país (AZEVEDO, 1999, p. 115).

No mesmo período, a administração federal sofreu grande reestruturação, tendo em vista o propósito de incluir metas a serem alcançadas em órgãos públicos e responsabilizar servidores em vistas da garantia de melhoria na prestação de serviços públicos. Buscava-se melhorar a capacidade da administração pública. Em virtude de tais intuitos, em 1936, criou-se o sistema de promoção por mérito para cargos públicos e, em 1938, o Departamento Administrativo do Serviço Público (DASP) (WAHRLICH, 1984, p. 49).

Segundo Bresser-Pereira (2009, p. 205-206) a reforma em apreço, denominada burocrática, teve como principais objetivos "transformar os burocratas profissionais em administradores públicos" e "combater o patrimonialismo, o clientelismo, a troca de favores". A característica, até então, patrimonialista da administração pública era incompatível com o modelo de mercado capitalista e com os novos mecanismos democráticos que estavam surgindo. 
Esse primeiro plano de reforma desenvolveu-se até 1945, mas com os governos de José Linhares (1945-1946) e Eurico Gaspar Dutra (1946-1951), os avanços na seara reformista não receberam o devido respaldo. Por tal razão, Bresser-Pereira (2009, p. 248) afirma que apesar da reforma burocrática ter estabelecido o serviço público profissional e as diretrizes da administração pública, ela nunca foi de fato concluída.

Com o retorno de Getúlio Vargas à presidência, em 1951, foram realizadas diversas tentativas para resgatar o fito reformista inicial e avançar nos planos anteriormente instaurados. Conquanto, o período de 1951 a 1963 ateve-se, essencialmente, ao desenvolvimento de estudos referentes à reorganização e descentralização das atividades do Estado (WAHRLICH, 1984, p. $51)$.

Marco importante no período de 1963 a 1967 foi a aprovação do Decreto-lei n. 200 de 25 de fevereiro de 1967, que apresentou uma reorganização das atividades do governo no âmbito da administração e trouxe um inédito desígnio fundamentado na eficiência administrativa. O início do aperfeiçoamento do modelo burocrático foi verificado com a instauração do regime militar brasileiro em 1964, que "ampliou e possibilitou maior eficiência da chamada Administração Indireta (autarquias, fundações, empresas públicas e sociedades de economia mista) (AZEVEDO, 1999, p. 115). Essa segunda reforma da administração pública foi chamada de desenvolvimentista, porque visou essencialmente promover o desenvolvimento econômico do país resolvendo os problemas relacionados à industrialização interna, que contava apenas com a atuação direta do Estado.

Com a Constituição da República Federativa do Brasil de 1988 e a partir de 1995, com a publicação do Plano Diretor da Reforma do Aparelho do Estado, a reforma administrativa gerencial foi efetivamente lançada no Brasil. Apesar das políticas de descentralização da prestação de determinados serviços para estados e municípios, delegação de poderes para órgãos regionais e políticas pontuais de privatização (BRESSER-PEREIRA, 2009, p. 251), não se propunha a redução do Estado. A reforma gerencial não apontou para a construção de um Estado mínimo, mas sim para a reorganização da forma de gestão da máquina pública e da intervenção do Estado sob o domínio econômico. Segundo Abrucio (1999, p. 163),

(...) reduziu-se o escopo de atuação direta do Estado, por meio de privatizações, concessões ou parcerias. Isso não significou a criação de um Estado mínimo, mas sim a redefinição do papel do Estado, reforçando suas funções indutoras e regulatórias, em detrimento do seu aspecto executor. 
Para essa reestruturação e como pressuposto para o exercício da administração gerencial, definiu-se quais seriam os âmbitos de atuação em que a presença do Estado seria necessária e imprescindível, denominando-a de "núcleo estratégico" (BRESSER-PEREIRA, 2009, p. 285). À parte, serviços não exclusivos do Estado poderiam ser prestados por organizações sociais, com apoio público. São os passos para o processo da publicização. Por fim, atividades que poderiam ser prestadas de maneira mais eficaz pela iniciativa privada e que não envolvessem os segmentos mencionados, foram para essa conferida (PACHECO, 1999, p. 232-233).

Percebe-se que, em verdade, o processo de reforma do Estado, ou reforma gerencial, ainda hoje, depende da construção diária de um Estado essencialmente republicano, envolvido com o aprimoramento dos seus servidores, atendimento dos seus cidadãos e eliminando práticas patrimonialistas. A reforma gerencial iniciada em 1995 abriu espaço para as discussões acerca da qualidade dos serviços prestados pela máquina pública, o tamanho do Estado em termos de concessão de direitos sociais, atuação da sociedade na esfera das decisões e para a eliminação da corrupção entre os servidores públicos. Percebe-se assim que ela teve claramente contornos democráticos, sociais, liberais e gerenciais.

\subsection{Reforma administrativa democrática, social, liberal e gerencial}

O aspecto democrático da reforma pode ser identificado na ampliação da participação do cidadão-cliente na avaliação e na co-gestão de serviços públicos. Diante de um país recentemente redemocratizado, a reforma atuou na criação e consolidação de instituições que garantiram a atuação do povo na esfera pública e um favorável cenário de governabilidade (ABRUCI, 1999, p. 164-165).

Esse processo de construção democrática é parte fundamental da reforma do Estado brasileiro, seja porque é preciso tornar mais transparente a administração pública e aumentar a participação e o controle da sociedade sobre o Poder Público, seja em razão da necessidade de realizar as reformas por meio das instituições políticas representativas, e portanto é preciso aperfeiçoar o funcionamento do sistema político (ABRUCI, 1999, p. 164).

O caráter democrático ainda é evidenciado na ampliação da transparência das ações do Estado, que passou a conferir o "acesso dos usuários a registros administrativos e a informações sobre atos de governo" (art. 37, $\S 3^{\circ}, \mathrm{II}, \mathrm{CF}$ ), conduta que repercutiu positivamente na accountability governamental (PACHECO, 1999, p. 223). A partir desse conhecimento, o 
cidadão passou a influir das decisões estatais, por meio de mecanismos promovidos pela própria reforma, como as audiências e consultas públicas ocorridas em entidades governamentais.

A marca social também é percebida na nova governabilidade que se torna atenta à "prestação de serviços cuja eficiência e qualidade devem ser aferidas pelo grau de satisfação manifestado pelos contribuintes-consumidores" (ALBUQUERQUE, 1995, p. 134). Ainda que não prestados diretamente, o Estado afirma seu papel de promotor, incentivador e garantidor de serviços sociais (BRESSER-PEREIRA, 2009, p. 253). Por intermédio da descentralização administrativa, esse garante que os serviços básicos sejam prestados com especialização e atendendo às necessidades regionais. Com tal prática, desonera-se o Estado e aumentam as possibilidades de garantir serviços de qualidade, sem afastar a intervenção do Estado por meio da regulamentação e de incentivos (ALBUQUERQUE, 1995, pp 147 e 174-175).

A transferência de algumas atuações públicas para a iniciativa privada e a apropriação de mecanismos dessa para implementação na administração estatal apontam ainda o seu caráter liberal. A proposta "acredita no mercado como um excelente, mas imperfeito, agente de alocação de recursos, e encara a contratação de serviços e a competição administrativa como excelentes ferramentas de responsabilização" (BRESSER-PEREIRA, 2009, p. 253).

Quanto aos controles tradicionais, mudam-se os seus objetos. Ou seja, ao invés de ser destinado apenas aos processos, passa a avaliar também os resultados. Isso não significa deixar de considerar a legalidade como elemento essencial do ato administrativo, mas sim de reconhecer que essa não é suficiente, se vista de modo único, para assegurar a legitimidade da ação pública (PACHECO, 1999, p. 234).

A partir de tais apontamentos, pode-se verificar que a reforma administrativa do Estado, iniciada em 1995 e que teve como marco legal a Emenda Constitucional n. 19 de 1998, foi social por passar a considerar o cidadão também como consumidor dos serviços públicos, que precisariam, para atendê-lo, serem prestados com qualidade e presteza. Foi ainda democrática, porque positivou mecanismos de atuação direta da sociedade na esfera pública, como reclamações relativas à prestação dos serviços públicos em geral (artigo 37, §3º I, CF) e acesso dos usuários às informações de caráter público (artigo 37, §3º II, CF).

É imprescindível considerar ainda o seu caráter liberal, tendo em vista que o Estado passa a contar com o mercado para a prestação de determinadas atividades, que não compõem o seu núcleo estratégico, iniciando um processo de privatizações em áreas específicas. Por fim, a reforma foi ainda gerencial porque, inspirada em práticas da iniciativa privada, flexibilizou e descentralizou a atuação da administração, promovendo a agilidade e a eficiência no âmbito 
público. A reforma do Estado, ocorrida a partir de 1995, buscou o equilíbrio entre a participação democrática, o atendimento ao cidadão, a ampliação do mercado e a promoção da eficiência administrativa.

\section{AGÊNCIAS REGULADORAS NO CONTEXTO DA REFORMA ADMINISTRATIVA GERENCIAL}

A primeira previsão no ordenamento jurídico brasileiro que atribuiu competência à União para a criação de um órgão regulador ocorreu com a publicação da Emenda Constitucional n. 8 de 1995. Essa, que introduziu o inciso XI no artigo 21 da Constituição Federal de 1988, definiu que a União poderia explorar, diretamente ou mediante autorização, concessão ou permissão, os serviços de telecomunicações, nos termos da lei. Ainda, pela norma do dispositivo, a essa lei caberia dispor sobre a organização dos serviços e a criação de um órgão regulador, atualmente representado pela Agência Nacional de Telecomunicações (Lei n. 9.472 de 1997, ANATEL). Em seguida, por meio da Emenda Constitucional n. 9 de 1995, foi prevista competência à União, nos termos do art. 177, §2² , III, da Constituição Federal de 1988, para estruturar e definir as atribuições do órgão regulador de monopólio da União sobre petróleo, gás natural e biocombustível, que atualmente é a Agência Nacional do Petróleo (Lei 9.478 de 1997 - ANP).

Várias agências reguladoras foram criadas após a Constituição Federal de 1988 e tiveram suas atuações definidas em Lei. Atualmente exercem, primordialmente, as funções de regulamentar e fiscalizar: i) os contratos administrativos de concessões de serviços públicos, tal qual a Agência Nacional de Energia Elétrica (Lei n. 9.427 de 1996, ANEEL); e, ii) de intervenção em setores de atuação pública ou privada de relevante interesse social, pois essas atividades podem provocar externalidades negativas de amplo alcance social, tal qual é a atuação da Agência de Vigilância Sanitária (Lei n. 9.782 de 1999 - ANVISA).

\subsection{Regime jurídico das Agências Reguladoras}

Em virtude da natureza da função a ser exercida pelas agências reguladoras, lhes foi conferido um regime jurídico especial, composto por "privilégios específicos que a lei outorga à entidade para a consecução de seus fins" (MEIRELLES, 2016, p. 451). Tais privilégios lhes garantem independência em relação ao governo e comprometimento frente ao Estado republicano. Havendo inserção política nessas entidades da administração indireta há distorção dos seus objetivos (CARVALHO FILHO, 2017, p. 326). 
Independentes, as Agências Reguladoras podem "decidir sobre questões de pessoal e questões organizacionais e financeiras que envolvam a organização" (BRESSER-PEREIRA, 2009, p. 306), sem controle prévio por parte do Ministério onde atuam. Além desta característica, seus dirigentes são escolhidos em razão do seu amplo conhecimento na área de atuação da autarquia, devem, após a escolha, passar pelo processo de "sabatina" realizado Senado Federal (artigo 52, inciso III, alínea f, Constituição Federal de 1988) e, com a nomeação pelo presidente, passam a ter mandado fixo e não coincidente com o mandato da presidência (MEIRELLES, 2016, p. 451).

A perda do mandato, antes do seu término, somente pode se dar por condenação judicial transitada em julgado ou falta administrativa devidamente apurada em processo administrativo disciplinar, não podendo seus dirigentes serem exonerados ad nuntum. $\mathrm{O}$ mecanismo protege-os da imposição de interesses mercadológicos e políticos (MEIRELLES, 2016, p. 451). Ademais, o regime jurídico dos servidores deve ser necessariamente estatutário, por serem órgãos do estado e não de governo e as promoções devem se dar após uma análise meritória, em que seja verificado o desempenho do servidor e o cumprimento das metas estabelecidas (BRESSER-PEREIRA, 2009, p. 307). Quanto a autonomia financeira, devem lhes serem garantidas receitas, na lei orçamentária, para que possam cumprir suas atribuições e projetos previstos na Lei de Diretrizes Orçamentárias (AMARAL, 2008, p. 72-73).

As referências da iniciativa privada na gestão dos interesses públicos por meio das agências reguladoras, enfatizam a competência normativa em nível regulamentar (atos administrativos) permitindo maior agilidade na normatização dos setores de atuação. Sua importante atuação de fiscalização para fazer cumprir as leis e regulamentos soma-se ainda à possibilidade de recorrer à solução extrajudicial de conflitos, atuações que destacam a característica gerencial das agências reguladoras.

\subsection{A competência normativa, fiscalizatória e de solução de conflitos}

O poder normativo conferido às agências se faz imprescindível em razão da necessidade de regulamentação técnica e científica dos setores regulados. Segundo Di Pietro (2016, p. 580), é possível “ (a) regular a própria atividade da agência por meio de normas de efeitos internos; (b) conceituar, interpretar, explicar conceitos jurídicos indeterminados contidos em lei, sem inovar na ordem jurídica". Cumpre frisar que esse se submete integralmente à lei e aos decretos regulamentares expedidos pelo poder Executivo, bem como ao controle externo pelo Congresso Nacional (artigo 49, inciso V, CF), que pode sustar os atos 
normativos do Poder Executivo que exorbitem do poder regulamentar ou dos limites de delegação legislativa, por não se tratar de competência normativa inaugural.

No que se refere à ANATEL, por exemplo, a competência normativa está delineada no artigo 19, IV, da Lei n. 9.472 de 1997, nos seguintes termos: "expedir normas quanto à outorga, prestação e fruição dos serviços de telecomunicações no regime público"; bem como, conforme inciso X: "expedir normas sobre prestação de serviços de telecomunicações no regime privado". Verifica-se que cabe a essa disciplinar tanto a transferência de serviços públicos para o setor privado quanto as regras para a atuação privada na prestação desses.

Quanto à função fiscalizatória, de acordo com Aragão (2003, p. 317), varia de acordo com a atividade precípua da agência. Quando essa atua regulando serviços públicos, a fiscalização é inerente ao poder concedente, por se tratar de relação contratual de serviços públicos. No que se refere à ANATEL, a fiscalização da execução, comercialização e uso dos serviços de telecomunicações está prevista no artigo $1^{\circ}$, parágrafo único, da Lei indicada. Quando a atuação das agências estiver voltada para setores considerados essenciais e de expressivo interesse público, a fiscalização do cumprimento de tais normas é o momento do exercício do poder de polícia em sentido estrito, tal qual é a ação fiscalizatória da ANVISA.

As agências reguladoras possuem ainda competência para recorrer aos meios de solução extrajudicial de conflitos, ou seja, caminhos consensuais tais quais a mediação, conciliação e arbitragem. A solução decorrente deste caminho não significa plena independência em relação ao poder judiciário, pois o controle judicial das decisões administrativas é constitucionalmente previsto (DI PIETRO, 2016, p. 579). Defende-se que a possibilidade de autocomposição poderá promover a eficiência na administração pública face, em especial, à possibilidade de acesso à justiça em nível administrativo e contribuir para a diminuição de demandas judiciais.

A previsão da atuação extrajudicial na resolução de conflitos, para exemplificar, está prevista no âmbito de atuação da ANATEL, conforme artigo 19, XVII da Lei n. 9.472 de 1997, ou seja, "compor administrativamente conflitos de interesses entre prestadoras de serviço de telecomunicações". É certo que tal competência no âmbito público é mais limitada do que na experiência privada. A justificativa é que envolve interesses qualificados no âmbito do regime jurídico público, que devem ser considerados em toda a atuação do Estado, até mesmo diante do espaço de liberdade que a lei deve prever para que o agente público possa buscar tais caminhos. 


\section{MEIOS DE SOLUÇÃO EXTRAJUDICIAIS DE CONFLITOS EM AGÊNCIAS REGULADORAS E A EFICIENCIA ADMINISTRATIVA}

A solução extrajudicial de conflitos constitui-se mecanismo ímpar da iniciativa privada. Isso porque, além de promover a pacificação social insere-se no âmbito de confiança das partes, que escolhem conjuntamente o terceiro interventor, diante as técnicas de conciliação, mediação e arbitragem.

As recentes discussões acerca da importância da utilização dos meios extrajudiciais de resolução de conflitos, em diversas áreas, possuem fundamento em soluções de lides privadas existentes antes mesmo do Estado Moderno (a partir do século XV). Inicialmente, as técnicas utilizadas limitavam-se à autodefesa e autotutela, apontando a doutrina para as primeiras utilizações da mediação na Antiguidade Chinesa (1766 a.C. - 618) (RICHE, 2001, p. 25).

Os meios de resolução extrajudiciais de conflitos são priorizados na esfera privada em razão da "celeridade, a confidencialidade, a especialização no tema a se decidir, a economia de recursos materiais e humanos, o menor grau de enfrentamento entre as partes, a flexibilidade, a maior participação das partes e a maior proximidade delas com o árbitro" (SALLES, 2011, p. 11), além de incentivar a pacificação social.

Destaca-se que tanto a arbitragem quanto à mediação tem como princípio fundante a autonomia da vontade. As partes optam por uma resolução extrajudicial, mesmo podendo recorrer diretamente ao Judiciário.

O procedimento célere, com resultados eficientes e de convergência de interesses, despertou o interesse na administração pública construída a partir da reforma do Estado, especialmente porque permite a ação social participativa como alternativa à solução judicial tradicional. São os caminhos da consensualidade que possibilitam a pacificação social e, sob aspecto técnico, são importantes porque permitem a atuação de terceiros dotados de conhecimentos por vezes mais específicos do que aqueles encontrados no judiciário. A "formação setorial adequada" faz do arbitro ou mediador o mais indicado para atuar em meio ao conflito, de modo a contribuir positivamente para a melhor e mais eficiente solução da demanda (BACELLAR, 2009, p. 59).

\subsection{A arbitragem e a solução de conflitos em âmbito da administração pública}


Nos termos de Marolla (2016, p. 09), "a arbitragem é meio privado de resolução de controvérsias, no qual as partes envolvidas, de comum acordo, atribuem a um terceiro o papel de solucionar a contenda, possuindo a decisão proferida, força de coisa julgada". Constitui-se em prática heterocompositiva e extrajudicial de resolução de conflitos, visto que depende da atuação de outrem que não se insere na demanda.

$\mathrm{Na}$ arbitragem um terceiro resolve o conflito, independentemente da manifestação das partes. Essas aderem à decisão proferida que, por imposta, não admite alteração por via judicial, nem mesmo por via recursal. Vale ressaltar que, mesmo na esfera privada, não é possível que qualquer demanda seja levada à arbitragem (FALÇÃO; GUERRA; ALMEIDA, 2015, p. 24). Há a necessidade de que a lide tenha, segundo Lee (2005, p. 51), "arbitrabilidade”, ou seja, que as pessoas físicas ou jurídicas sejam aptas a se submeter à técnica e que o objeto comporte a heterocomposição.

A arbitragem para o âmbito privado foi regulamentada no Brasil a partir da publicação da Lei n. 9.307 de 1996. Atendendo aos requisitos da "arbitrabilidade" mencionados, o instituto legal estabeleceu, em seu artigo $1^{\circ}$ que "as pessoas capazes de contratar poderão valer-se da arbitragem para dirimir litígios relativos a direitos patrimoniais disponíveis”. Além disso, a lei estabeleceu diretrizes para as cláusulas compromissórias, escolha do árbitro imparcial, convenção de arbitragem e demais regramentos do procedimento.

Marco importante do tema foi a publicação da Lei n. 13.129 de 2015, que autorizou a utilização da arbitragem pela administração pública, nos seguintes termos "a administração pública direta e indireta poderá utilizar-se da arbitragem para dirimir conflitos relativos a direitos patrimoniais disponíveis". Com tal competência, a arbitragem pode ser utilizada no âmbito da administração indireta, onde estão as autarquias, inclusive as em regime especial, tratadas na pesquisa.

Com a publicação da Lei n. 9.478 de 1997, que dispôs sobre a política energética nacional e as atividades relativas ao monopólio do petróleo, o legislador positivou a obrigatoriedade de a administração pública instituir no contrato de concessão como cláusula essencial "as regras sobre solução de controvérsias, relacionadas com o contrato e sua execução, inclusive a conciliação e a arbitragem internacional" (artigo 43, X, Lei n. 9.478 de 1997).

Posteriormente, a Lei n. 8.987 de 1995, que dispõe sobre o regime de concessão e permissão da prestação de serviços públicos, que foi alterada pela Lei n. 11.196 de 2005, incluiu a possibilidade de o contrato de concessão "prever o emprego de mecanismos privados para resolução de disputas decorrentes ou relacionadas ao contrato, inclusive a arbitragem, a ser 
realizada no Brasil e em língua portuguesa" (artigo 23-A). A Lei n. 9.472 de 1997 (ANATEL), prevê a possibilidade da agência "compor administrativamente conflitos de interesses entre prestadoras de serviço de telecomunicações” (artigo 19, inciso XVII, Lei n. 9.472 de 1997).

Conforme defende Amaral (2008, p. 19-25), quando da realização de composição de conflitos por agências reguladoras no âmbito das concessões, é possível que essas enfrentem demanda envolvendo a autoridade concedente (Estado), empresas privadas (concessionárias e permissionárias) e o próprio consumidor. Independentemente de quem estará envolvido na lide, sempre será um servidor público o árbitro, tendo em vista o regime jurídico dos servidores dessas autarquias especiais.

Ademais, diante da obrigatoriedade da licitação para concessão e permissão de serviços públicos o edital deve prever a arbitragem, sob pena de sua nulidade. Não é possível que o Estado imponha a arbitragem ao contratante posteriormente à assinatura do contrato, justamente porque "a arbitragem pode ser um fator determinante da decisão do particular quanto a participar ou não da licitação" (SALLES, 2011, p. 110).

No que se refere ao consumidor, esse deverá ser notificado, após instaurado o conflito. Embora não seja obrigado a aderir ao procedimento arbitral, deve ser informado acerca da possibilidade da sua utilização e dos seus benefícios. Caso haja a aceitação, é certo que a sentença arbitral o vinculará, mas esse não poderá debater sobre as condições da cláusula arbitral, porque essa é instituída no regulamento da agência. O consumidor poderá aderir a arbitragem ou optar por seguir judicialmente com a demanda (BACELLAR, 2009, p. 108).

Em seus estudos, Parada (2000, p. 559) destaca a necessidade de observar a imparcialidade da agência ao arbitrar acerca da demanda. Tendo em vista não ser a agência submetida hierarquicamente a outro órgão, essa exigência é fundamental para que a sentença arbitral seja legítima. Huergo Lora (2000, p. 260) entende que a neutralidade nunca será possível, em virtude de a administração buscar, sempre a tutela do interesse público. Salles (2011, p. 53), por sua vez, acredita na neutralidade no árbitro, cuja escolha deve evitar "arranjos institucionais que conduzam, por suas características, a uma precária ou tendenciosa consideração dos interesses do Estado".

A necessidade de motivação da decisão é princípio fundamental do procedimento arbitral, "uma vez que não há processo legítimo quando as partes não sabem se as razões por elas trazidas ao julgador foram ou não levadas em consideração quando da prolação da decisão" (BACELLAR, 2009, p. 149). A previsão de publicação da decisão arbitral também atende a obrigatoriedade de publicidade e transparência dos atos administrativos (art. 37, caput, $\mathrm{CF} / 88$ ). 
A autorização legal para arbitragem, no âmbito das agências, não afasta o controle por parte do Judiciário, tendo em vista que "as decisões proferidas na última instância administrativa podem ser revisadas judicialmente" (FALCÃO; GUERRA; ALMEIDA, 2015, p. 133). O laudo arbitral ainda poderá ser anulado diante de diversas previsões legais, entre elas, quando não houver o compromisso de adesão das partes e a decisão for proferida fora dos limites da cláusula arbitral.

Quando a solução do conflito envolve diretamente o poder público, destaque-se, que há necessidade de se observar se os interesses ali discutidos são disponíveis ou não. Havendo a indisponibilidade de interesses, conforme previsão no artigo $1^{\circ}, \S 1^{\circ}$ da Lei de Arbitragem (Lei n. 9.307 de 1996 com alteração pela Lei n. 13.129/15), é proibida a adesão ao procedimento arbitral. Diante desse cenário, necessário se faz analisar quais os interesses seriam disponíveis e que permitiriam o envolvimento Estatal nesses mecanismos de solução de conflitos.

Em suas conclusões, Muniz (2004, p. 93) afirma que a análise do conceito de patrimônio disponível perpassa pela verificação dos atos de império e de gestão do ente público. Segundo o autor,

os atos de império (ius imperium) são praticados pela Administração com supremacia sobre as demais partes, para a consecução de interesse público superior. Nos atos de gestão (ius gestionis), por sua vez, o Estado não objetiva fim público e, por isso, encontra-se no mesmo patamar das outras partes.

Quando a administração desenvolve relações jurídicas com conteúdo mercantil e sob a prevalência de atos de gestão, a adoção das técnicas de solução de conflitos mencionadas é positiva, vez que possibilita a celeridade da resolução do conflito (TÁCITO, 2005, p. 143). Marolla (2016, p. 120) concorda com o entendimento. Segundo a autora, a análise dos atos administrativos considerados de império e de gestão permite separar as atuações em que o Estado se vale das suas prerrogativas públicas e que, consequentemente, precisam ser submetidas ao judiciário. As atividades de gestão, ao contrário daquelas, podem ser inseridas no âmbito da Lei de Arbitragem, por se constituírem como "disponíveis".

Os principais argumentos contrários à utilização da arbitragem e da mediação pelas agências estão na possibilidade de violação da supremacia do interesse público e da indisponibilidade do interesse público (FALCÃO; GUERRA; ALMEIDA, 2015, p. 111). Contra argumenta Amaral (2008, p. 103) que a tutela de conflitos por meios alheios ao judiciário atende ao interesse público pois também possibilita a “correta aplicação da lei e com 
a realização concreta da justiça”. Portanto, se estes caminhos extrajudiciais forem percorridos com cumprimento de preceitos constitucionais, tais quais o contraditório, ampla defesa, duração razoável do processo e cumprimento do devido processo legal, atenderá ao interesse público e a eficiência.

\subsection{A mediação e a solução de conflitos em âmbito da administração pública}

Além da arbitragem, a mediação é mecanismo de resolução extrajudicial de resolução de conflitos criado para atender às necessidades existentes nas relações privadas de compor conflitos e alcançar a pacificação social. Essa, é "técnica de solução de conflitos por intermédio da qual um terceiro [denominado mediador] tem a função de aproximar as partes com o fito dos próprios litigantes, direta e pessoalmente, darem fim ao conflito" (RICHE, 2001, p. 26).

Segundo Moreira Neto (2001, p. 12), "na mediação, as partes acordam que um terceiro, de confiança de ambas, oferecerá uma solução capaz de compor satisfatoriamente o conflito, embora não as obrigue". Trata-se, em suma, de uma decisão autocompositiva, vez que, privilegiando-se o consensualismo, afasta-se a imposição de uma decisão. Não é obrigatório que as partes alcancem a resolução do conflito, mas, quando aderem à medição, se propõem a reunir-se para discutir acerca das possibilidades de solução (BACELLAR, 2009, p. 96).

Anos após a regulamentação da arbitragem, conforme mencionado, em 1996, a mediação também foi positivada por meio da Lei 13.140 de 2015. Segundo artigo $1^{\circ}$, parágrafo único da lei, "considera-se mediação a atividade técnica exercida por terceiro imparcial sem poder decisório, que, escolhido ou aceito pelas partes, as auxilia e estimula a identificar ou desenvolver soluções consensuais para a controvérsia". Além de conferir o conceito técnico, o instituto legal fortaleceu o uso da mediação no âmbito privado, pois instituiu seus princípios orientadores e estabeleceu regras para a escolha do mediador e desenvolvimento do procedimento.

Relativamente à mediação, em sua atuação, a agência se coloca como intermediadora de conflitos, auxiliando as partes a conversarem sobre o objeto da lide, orientando a discussão, apontando os pontos positivos da resolução extrajudicial e estimulando a solução que atenda ao interesse equilibrado de ambas as partes (BACELLAR, 2009, p. 97). A agência, como mediadora, não faz imposição de soluções, mas estimula e auxilia a resolução (FALCÃO, GUERRA, ALMEIDA, 2015, p. 21). 
A atuação do mediador, vinculado à agência, permite que a instrução do procedimento ocorra com base em conhecimentos técnicos e específicos. Para deflagrar esta competência, no caso do regimento da ANATEL (Resolução n. 612/13), "as prestadoras de serviços de telecomunicações poderão requerer à Anatel a instauração do Procedimento de Mediação, visando a solução consensual de questões relativas ao reconhecimento ou atribuição de direitos". Este requerimento atende o seu princípio essencial: autonomia da vontade (FALCÃO; GUERRA; ALMEIDA, 2015, p. 28). Não cabe à ANATEL impor às partes a utilização da técnica, mas sim esperar a manifestação dessas com relação ao interesse em aderir.

Para instauração da mediação, a autarquia especial, após analisar o requerimento inicial e, concordando com a demanda, deverá intimar as partes para reunião de acordo (art. 94, I e III, Resolução n. 612 de 2013). Havendo consenso, será celebrado o Termo de Acordo, que se submete à análise da autoridade hierarquicamente superior àquela que instaurou o procedimento de mediação (art. 94, VII e VIII, Resolução n. 612 de 2013). Com o acordo, segue-se para a homologação e "é irrecorrível a decisão que homologa o acordo entre as partes, a qual terá plena validade e vinculará as partes a partir de sua homologação" (art. 94, $\S 3^{\circ}$, Resolução n. 612 de 2013). Não havendo consenso, é possível que as partes busquem um outro meio de resolução extrajudicial do conflito tal qual a arbitragem (art. 94, X, Resolução n. 612 de 2013).

A mediação apresenta diversos benefícios quando alocada no âmbito das agências, tendo em vista que a solução parte dos próprios envolvidos e o conflito quando eliminado, possivelmente, não gerará outros da mesma espécie. Isso se dá pelo fato de que as partes, além de resolverem a lide, descobrem as razões pelas quais ela se deu e tendem à evita-la. Segundo Falcão, Guerra e Almeira (2015, p. 21) a mediação "é um processo orientado a possibilitar que as pessoas nele envolvidas sejam coautoras da solução e da resolução dos seus conflitos".

A experiência do caminho extrajudicial de solução de conflitos que ocorre na agência reguladora ANATEL está em compasso com as diretrizes de uma administração gerencial. A especialidade da agência permite que as demandas sejam solucionadas de modo a melhor atender aos interesses das partes e efetivamente alcançar a pacificação social. Ainda que envolvendo o Estado, a utilização da mediação e da arbitragem atendem ao interesse público, que valoriza a resolução de demandas de maneira célere, com mais técnica e eficiência.

\section{CONCLUSÃO}


O pilar fundamental da atuação da administração pública gerencial, em sua função administrativa, é o valor da eficiência conforme a Emenda Constitucional n. 19 de 1998. A eficiência não desconsidera as conquistas dos controles da administração pública burocrática, mas sim seleciona-os e imprime outros essenciais para condução das competências públicas conforme a ordem jurídica. Para alcançar este objetivo, várias mudanças podem ser implementadas na gestão pública, inclusive, aquelas testadas na gestão de interesses privados, desde que compatíveis com o regime jurídico de direito público.

Dentre as inovações trazidas pela Constituição Federal de 1988, e que podem ser incluídas no quadro da reforma do Estado, destaca-se a criação de um regime jurídico especial para as autarquias denominadas agências reguladoras. Esse permite que as agências possam desempenhar suas competências de modo independente e autônomo, pois são órgãos de Estado e não de governo, diferentemente das demais autarquias regidas pelo regime do Decreto-lei n. 200 de 1967.

As agências reguladoras no Brasil têm atribuições regulamentares e de fiscalização e atuam nas relações que envolvem concessão e permissão de serviços públicos (tal qual a ANATEL) e no âmbito público ou privado em atividades consideradas por lei essenciais para a sociedade (tal qual a ANVISA). Dentre as experiências de sucesso das relações privadas, que podem ser utilizadas pelas agências, está a solução extrajudicial de conflitos, por meio da arbitragem (artigo $1^{\circ}$, parágrafo $1^{\circ}$ da Lei n. 9307 de 1996) e a mediação (artigo $1^{\circ}$, parágrafo único, da Lei n. 13.129 de 2015).

A solução de conflitos por meio da esfera administrativa consensual é um avanço em termos de eficiência, pois além da participação deliberativa dos envolvidos, possibilita flexibilidade, tecnicidade e celeridade nestes processos administrativos. No entanto, em face do princípio da indisponibilidade do interesse público, deve-se perquirir sobre os limites da administração pública ao recorrer a opção extrajudicial. Defende-se que a partir da própria lei que confere tais competências, é possível identificar o interesse público a ser protegido, além dos princípios que regem a administração pública, ambos, limites para a inserção do Estado em soluções extrajudiciais de resolução de conflitos.

Ressalte-se que tanto para a arbitragem quanto para a mediação os textos legais que autorizam tais técnicas empregam termos abertos, tais quais, o limite de que os direitos patrimoniais sejam disponíveis (arbitragem) e somente as controvérsias que possam ser resolvidas sem autorização do Poder Legislativo (mediação). Sob tais aspectos, para o controle interno, externo e social do exercício de competências nestes campos de discricionariedade, 
exige-se a fundamentação legal, a identificação do motivo, observar os procedimentos e a motivação.

Em face do exposto, é possível afirmar que o regime da administração pública gerencial, a Lei n. 9307 de 1996 e a Lei n. 13.129 de 2015, permitem construir um regime jurídico para a solução extrajudicial de conflitos nas agências reguladoras. Estão abertas as possibilidades da eficiência previstas na Constituição Federal de 1988.

\section{REFERÊNCIAS}

ABRUCIO, Fernando Luiz. O longo caminho das reformas nos governos estaduais: crise, mudanças e impasses. In: MELO, Marcus André (Org.). Reforma do Estado e mudança institucional no Brasil. Recife: Massangana, 1999. p. 161-198.

ALBUQUERQUE, Roberto Cavalcanti de. Reconstrução e reforma do Estado. In: VELOSO, João Paulo dos Reis; ALBUQUERQUE, Roberto Cavalcanti de (coord.). Governabilidade e Reformas. Rio de Janeiro: José Olympio, 1995. p. 129-198.

AMARAL, Alexandra da Silva. Princípios estruturantes das agências reguladoras e os mecanismos de controle. Rio de Janeiro: Lumen juris, 2008.

ARAGÃO, Alexandre Santos de. Agências Reguladoras e a evolução do Direito Administrativo Econômico. 2. ed. Rio de Janeiro: Forense, 2003.

AZEVEDO, Sérgio de. Reforma do Estado e mudança institucional: variáveis exógenas e endógenas. In: MELO, Marcus André (Org.). Reforma do Estado e mudança institucional no Brasil. Recife: Massangana, 1999. p. 111-142.

BACELLAR, Luiz Ricardo Trindade. Solução de controvérsias pelas agências reguladoras. Rio de Janeiro: Lumen Juris, 2009.

BRESSER-PERERIA, Luiz Carlos Bresser. Construindo o Estado republicano: democracia e reforma da gestão pública. Rio de Janeiro: FGV, 2009.

BRESSER-PERERIA, Luiz Carlos Bresser. Uma reforma gerencial da administração pública no Brasil. In: PETRUCCI, Vera; SCHWARZ, Letícia (Orgs.). Administração pública gerencial: a reforma de 1995. Ensaios sobre a reforma administrativa brasileira no limiar do século XXI. Brasília: Universidade de Brasília: 1999. p. 17-62.

CARVALHO FILHO, José dos Santos. Manual de direito administrativo. 31. ed. São Paulo: Atlas, 2017.

FALCÃO, Joaquim; GUERRA, Sérgio; ALMEIDA, Rafael (Orgs.). Soluções alternativas de controvérsias no setor público. Rio de Janeiro: FGV, 2015. 
HUERGO LORA, Alejandro. La resolution extrajudicial de conflitos en el derecho administrativo: la transacción, el arbitraje y la reforma de los recursos administrativos. Bolonio: Publicaciones del Real Colegio de Espanã, 2000.

LEE, João Bosco. Arbitragem comercial internacional nos países do Mercosul. Curitiba: Juruá, 2005.

MAROLlA, Eugenia Cristina Cleto. A arbitragem e os contratos da Administração Pública. Rio de Janeiro: Lumen Juris, 2016.

MEIRELLES, Hely Lopes. Direito administrativo brasileiro. 42. ed. São Paulo: Malheiros, 2016.

MORAES, Alexandre de. Reforma administrativa: emenda constitucional 19/98. 3. ed. São Paulo: Atlas, 1999.

MOREIRA NETO, Diogo Figueiredo de. Mutações do Direito Administrativo. 2. ed. Rio de Janeiro: Renovar, 2001.

MUNIZ, Joaquim de Paiva. Os limites da arbitragem nos contratos de concessão de exploração e produção de petróleo e gás natural. Revisa Arbitragem e Mediação, São Paulo, v. 1, n. 2, p. 90-101, maio/ago. 2004.

PACHECO, Regina Silva. Reformando a administração pública no Brasil: eficiência e accountability democrática. In: MELO, Marcus André (Org.). Reforma do Estado e mudança institucional no Brasil. Recife: Massangana, 1999. p. 223-237.

PARADA, Ramón. Derecho Administrativo I: parte general. 12. ed. Madrid: Ediciones Jurídicas y Sociales, 2000.

RICHE, Cristina Ayoub. Lei de arbitragem n. 9.307/97: uma solução alternativa para conflitos de ordem jurídica. Rio de Janeiro: UniverCidade, 2001.

SALLES, Carlos Alberto de Salles. Arbitragem em contratos administrativos. Rio de Janeiro: Forense; São Paulo: Método, 2011.

TÁCITO, Caio. Arbitragem nos litígios administrativos. Revista de Direito Administrativo, Rio de Janeiro, v. 242, out./dez. 2005.

WAHRLICH, Beatriz. A Reforma Administrativa no Brasil: experiência anterior, situação atual e perspectivas - uma apreciação geral. Revista Administração pública. Rio de Janeiro, v. 18, n. 1, p. 49-59, jan./mar., 1984. 